UCRL-JC-119956

PREPRINT

CONF950455--2

\title{
Energy Absorption in Aluminum Extrusions for a Spaceframe Chassis
}

\author{
R. W. Logan \\ S. A. Perfect \\ R. D. Parkinson
}

This paper was prepared for submittal to the Proceedings of SAE-WSM

Troy, MI

April 14, 1995

September 19, 1994



This isa preprint of a paper intended for publication in a journalor proceedinga. Since changes may be made before publication, this preprint is made available with the understanding that it will not be cited or reproduced without the permiesion of the author.

DISTPIBUTION OF THIS DOCUMENT IS UNLIMITED 85

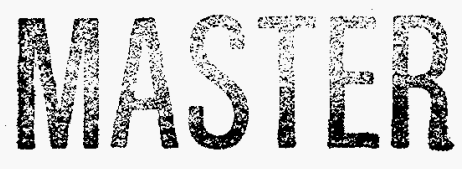




\section{DISCLAIMER}

This document was prepared as an account of work sponsored by an agency of the United States Government. Neither the United States Government nor the University of California nor any of their employees, makes any warranty, express or implied, or assumes any legal liability or responsibility for the accuracy, completeness, or usefulness of any information, apparatus, product, or process disclosed, or represents that its use would not infiringe privately owned rights. Reference herein to any specific commercial product, process, or service by trade name, trademark, manufacturer, or otherwise, does not necessarily constitute or imply its endorsement, recommendation, or favoring by the United States Government or the University of California. The views and opinions of authors expressed herein do not necessarily state or reflect those of the United States Government or the University of California, and shall not be used for advertising or product endorsement purposes: 


\section{DISCLAIMER}

Portions of this document may be illegible in electronic image products. Images are produced from the best available original document. 


\title{
ENERGY ABSORPTION IN ALUMINUM EXTRUSIONS FOR A SPACEFRAME CHASSIS
}

\author{
Roger W. Logan \\ Scott A. Perfect \\ University of California \\ Lawrence Livermore National Laboratory \\ (LLNL) \\ Livermore, CA \\ Ray D. Parkinson \\ Kaiser Aluminum \& Chemical Corporation \\ (Kaiser Aluminum) \\ Center for Technology \\ Pleasanton, $\mathrm{CA}$
}

\begin{abstract}
This work describes the design, finite-element analysis, and verifications performed by LLNL and Kaiser Aluminum for the prototype design of the CALSTART Running Chassis purpose-built electric vehicle. Component level studies, along with our previous experimental and finite-element works, provided the confidence to study the crashworthiness of a complete aluminum spaceframe. Effects of rail geometry, size, and thickness were studied in order to achieve a controlled crush of the front end structure. These included the performance of the spaceframe itself, and the additive effects of the powertrain cradle and powertrain (motor/controller in this case) as well as suspension. Various design iterations for frontal impact at moderate and high speed are explored.
\end{abstract}

\section{INTRODUCTION AND BACKGROUND}

The expense of powertrain systems for electric vehicles, along with a low energy density for storage, has stimulated the many current efforts to examine the integrated design of purpose-built electric vehicles using lightweight materials for the load-bearing structures while maintaining structural soundness and adequate crashworthiness. As a participant in the CALSTART Running Chassis program, Kaiser Aluminum's Center For Technology (CFT) has fabricated and tested various aluminum extrusion geometries for use in the subsequent construction of a prototype aluminum spaceframe for the vehicle. Simultaneously, Lawrence Livermore National Laboratory (LLNL) is leveraging its traditional mission in finite-element code technology for weapons design and safety $[1, .2]$ by collaborating with industry on development programs for impact safety and crashworthiness. The work has involved integration of handling and deformation codes, development of material and tire models, and comparisons to test data. In a recent example of such a collaboration, LLNL and Kaiser Aluminum have conducted a study keyed toward the use of aluminum extrusions in a space-frame vehicle design.

We have recently completed the design and fabrication of an aluminum spaceframe chassis for an electric vehicle purpose-built prototype. This work describes the final component (rail) level design analysis, followed by analysis of the full spaceframe in frontal crush and roof crush.

At the component level, we have explored the effect of rail thickness on crash energy absorption for rectangular cross-section rails made from extruded aluminum and several generic materials. Previous experimental studies have indicated that the crush energy absorbed by tubes varies approximately as the tube thickness raised to the 1.6 to 1.8 power $[3,4]$. We have studied this phenomenon with our DYNA3D finite-element code and found this trend to be duplicated numerically.

Component level studies, along with our previous experimental and finite-element works [5-8], provided the confidence to study the crashworthiness behavior of a complete aluminum spaceframe. Effects of rail geometry, size, and thickness were studied in order to achieve a controlled crush of the front end structure. Since the design itself was intended to be modular, we planned to explore the energy absorption process in several steps. These included the performance of the spaceframe itself and the additive effects of the powertrain cradle and powertrain (motor/controller in this case). Analyses were planned with and without suspension and unsprung components to determine their effects. Various designs for the toprail area were used to control the geometric progression in crush. In the process, much was learned about the quantitative and qualitative behavior of the aluminum spaceframe and the major reactive masses (motor assembly and wheel/tire) during frontal crush.

\section{VEHICLE CONCEPT}

The basic concept of the CALSTART Running Chassis was to provide a purpose-built plattorm for electric vehicles with current and future options for powertrain, and at the same time provide a high degree of modularity to allow vehicles for different missions (sedan, sports, utility, etc.) to spin off from the same platform at low volumes. The benefits of aluminum for lightweight crashworthy vehicles have been discussed previously [9]. Extrusions offer lower cost tooling and design flexibility, factors particularly important in low volume applications such as those envisioned for the Running Chassis Program. A key feature in this design 
process involves both the thermomechanical processing of the selected $6 \times x \times$ alloy [8], as well as the joint design, as discussed in other studies $[10,11]$. New procedures involving adhesives and interlocking mechanisms were used for the chassis assembled here, and these will be addressed in a future work. The designs and processes used in the Running Chassis are currently subject to Kaiser Aluminum patent applications precluding an indepth discussion at this time.

The product of numerous design meetings at CALSTART was a plan for a prototype build of a platform chassis for a five-passenger four-door sedan. The prototype was built and completed in February 1993. During that period and since, further testing and finite-element crashworthiness calculations have provided input for future prototypes including several design variations discussed below. The basic plattorm shares common dimensions including an aluminum spaceframe weight of about $127 \mathrm{~kg}$., a curb weight of $1230 \mathrm{~kg}$. for the vehicle (with lead-acid batteries as the first-generation power source), a GVW of $1690 \mathrm{~kg}$. with a front/rear curb weight split of about 50/50. The platform has a wheelbase of $2667 \mathrm{~mm}$, and front track of 1473 $\mathrm{mm}$ and rear track of $1448 \mathrm{~mm}$. During this study, our goal was to examine the energy absorption behavior of the vehicle during frontal and roof crush, with side impact to be addressed on a case-by-case basis as the outer body and interlocking door structure is determined for each application.

\section{MODEL DEVELOPMENT}

Development of a finite-element model for the spaceframe and payload began with solid model and IGES file generation and translation using PTC ProEngineer packages [12]. The resulting IGES data was used by the TrueGrid mesh generator [13] providing flexibility in changing both the geometry and mesh as various design options were considered. The resulting finite-element mesh (Fig. 1) was prepared as an input deck for a version of LLNL's DYNA3D code with special features for modeling the crush of both the aluminum extrusions as well as the tire compression and blowout phenomenon. These special features will be discussed in detail at a later date, but we note that they added greatly to the the computational efficiency of the model, allowing symmetric half-model frontal impacts with over 7000 elements to be performed in only a few hours of Silicon Graphics R4000 computer time.

\section{EXTRUSION TESTING AND ANALYSIS}

In addition to the studies on axial crush performed previously [8], numerous bend tests on the extrusions and joints were conducted to assure that high energy absorption processes would be attained without premature failure in the joints. This required Kaiser Aluminum to design and test adhesively bonded joints with interlocking features and external reinforcements. The DYNA analysis of one such joint is shown in Fig. 2, with the stem of the " $T$ " joint being loaded in bending until buckling begins just outside the joint area. Comparisons between the test data and DYNA analyses showed good agreement in the load-deflection behavior. DYNA loading velocities varying from 2 to 12 meters $/ \mathrm{sec}(\mathrm{m} / \mathrm{s})$ showed nearly identical results, and these closely matched the quasi-static test results.


Fig. 1: UPPER: Prototype Running Chassis. LOWER: Finite-element mesh prepared for DYNA3D using ProEngineer and TrueGrid. 



Fig. 2: DYNA analysis of an experimental bend test on a "T" extrusion section, with bucking just outside the joint area as designed.

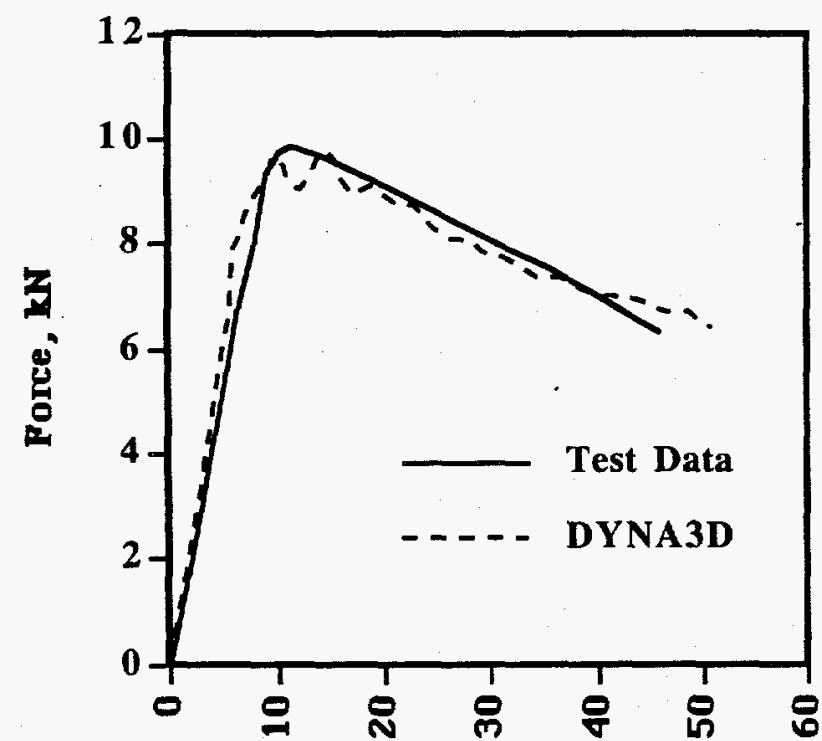

Deflection, mm

Fig. 3: Comparison of test data for the bend test of the previous figure with DYNA analysis data.
In preparation for the design iterations to follow, we chose to re-examine the correlation of energy absorption in axial crush of rectangular members with thickness $[3,4]$ indicating a dependence of energy absorbed on thickness $t$ of about $t^{1.6}$ to $t^{1.8}$ power. These trends are reproduced in the DYNA analyses shown in Fig. 4. The same trend in exponent holds for several different values of normalized flow strength over the approximate range of steels and aluminums as candidate materials for energy absorption. The energy absorption is very nearly linear in normalized flow stress but superlinear as expected in thickness ratio.
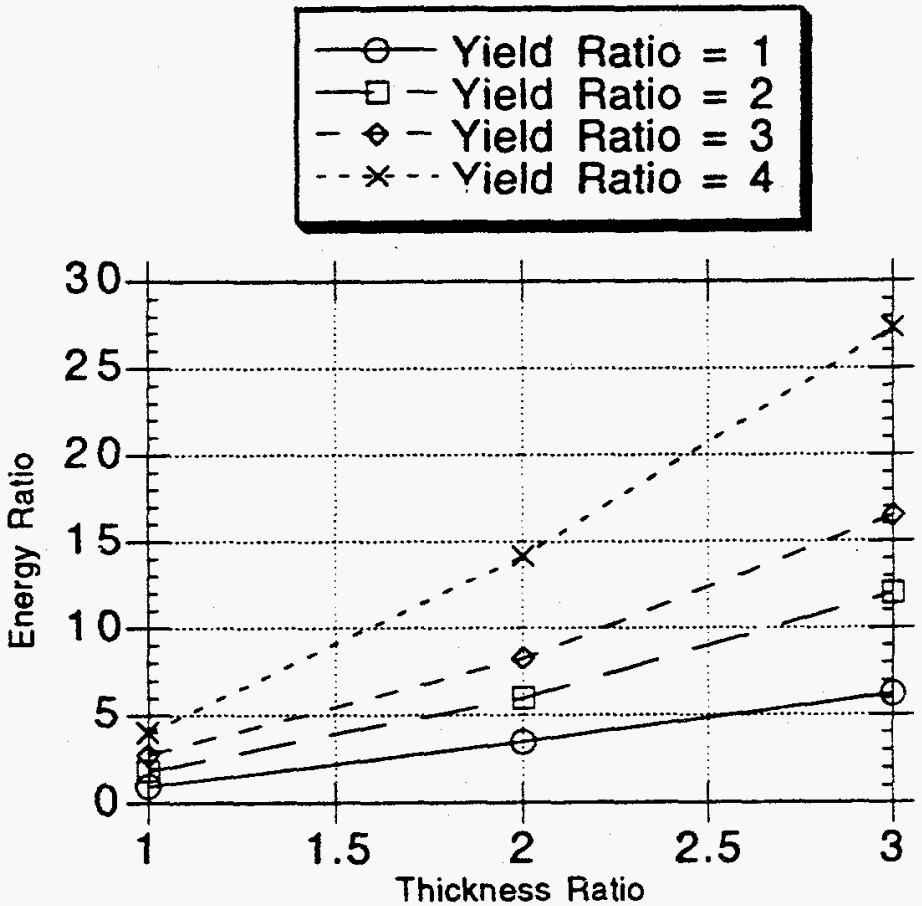

Fig. 4: Trends of energy absorbed versus box-section thickness as calculated by DYNA. Experimentally demonstrated dependencies are reproduced.

\section{ROOF CRUSH ANALYSIS}

To assure that the proper extrusion thicknesses were chosen for the roof structure, the FMVSS 216 conditions for roof crush were analyzed using lowvelocity $(2-8 \mathrm{~m} / \mathrm{s})$ impacts of the test device with the roof structure. The resulting impact and deformation of the A-pillar and roof rail are shown in Fig. 5. A number of analyses were performed and the force-deflection plotted to assure that adequate choices of extrusion thickness, mesh and impact velocity were used and that the 216 requirements would be met. These results are shown in Fig. 6 , showing only a minor dependence on impact speed (Fig. 6a) and mesh density (FIg. 6b), thus allowing for ease of comparison of the effect of extrusion thickness on crush force developed (Fig. 6c). The requirement of 1.5 times the curb weight of $1230 \mathrm{~kg}$. should be easily surpassed. 

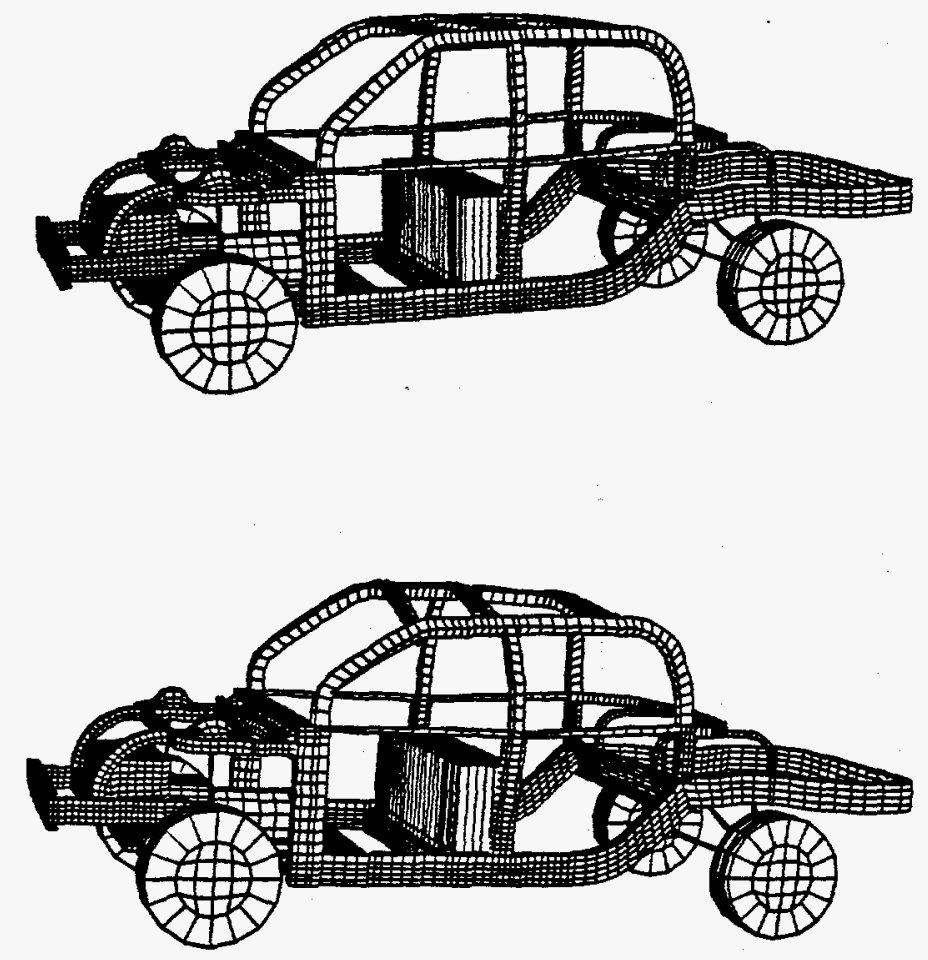

Fig. 5: Graphical illustration of the deformation of the roof and A-pillar during FMVSS 216 simulations.

\section{FRONTAL IMPACT ANALYSIS}

Numerous frontal impact simulations were performed on both the initial prototype (Design " $A$ ") as produced, and on subsequent design iterations that were examined in an effort to optimize the frontal structure for energy management using the current powertrain. The vehicle uses a controller box / transaxle / electric motor in an inline arrangement reminiscent in length to an internal combustion straight-six or even straight-eight arrangement. However, availability of drive components and packaging for power delivery efficiency and safety drive the layout. The result, as shown graphically in subsequent DYNA plots, is that the lengthy powertrain


Fig. 6: Force-deflection for the roof crush analysis (FMVSS 216) using DYNA. UPPER) effect of impactor velocity used in DYNA to approximate the quasi-static test. MIDDLE) effect of refining the mesh by halving the element side lengths. LOWER) Effect of extrusion thickness range on peak crush force. 


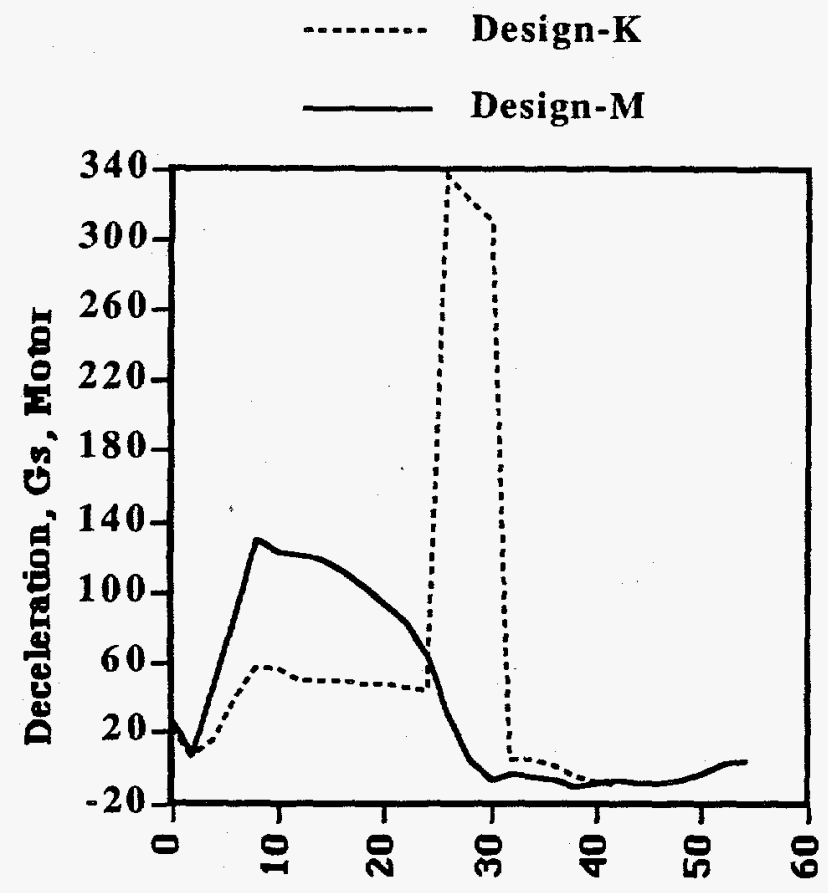

Time, ms

a)

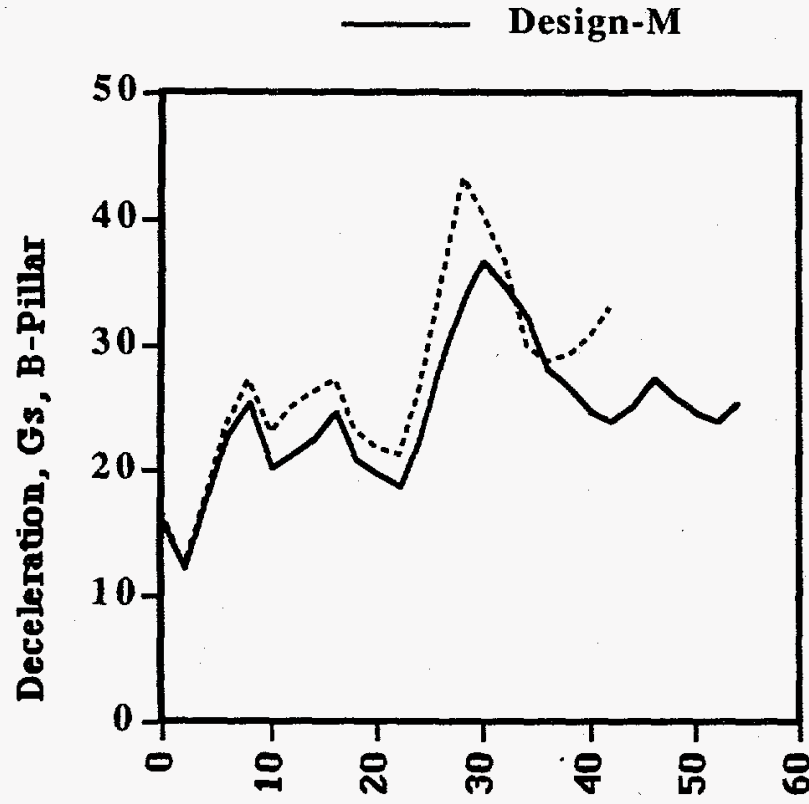

Time, ms

b)

Fig. 7. Comparison of Designs $K$ and $M$ (controller strength issue) at $v=26.8 \mathrm{~m} / \mathrm{s}$ frontal impact. Early motion of the powertrain is needed for good deep crush behavior. a) High peak G's in motor just beyond 208 crush level in " $\mathrm{K}$ " design, with improvements in " $M$ " design. b) Resulting improvement in B-pillar G's. assembly is a major impediment in meeting the objectives of a smooth crash pulse with minimal intrusion. A striking example of this is illustrated in Fig. 7, showing a comparison of two of the many design

iteration calculations. Design "K" was an attempt to minimize the contribution of the controller box and transaxle/motor during the moderate crush levels attained in the FMVSS $208(\mathrm{v}=10.4 \mathrm{~m} / \mathrm{s})$ test. It is important to note that the majority of the design calculations were performed at initial impact velocities of $v=26.8 \mathrm{~m} / \mathrm{s}$ to permit evaluation of the energy management process through the near-complete crush of the front clip. At such velocity, the FMVSS 208 crush displacement of about $51 \mathrm{~cm}$ is reached at $20-22 \mathrm{~ms}$. The motor deceleration shown in Fig. 7a shows that Design "K" does well up to this point, with a fairly smooth B-pillar response (Fig. $7 b$ ) post-processed to approximately a $250 \mathrm{~Hz}$ lowpass filter level. However, an obvious potential problem would arise if the controller box was made to be this weak during an NCAP impact of $15.6 \mathrm{~m} / \mathrm{s}$ or higher. The transaxle/motor combination is suddenly forced into motion at a crush level just beyond the 208 test, resulting in tremendous $G$ 's to these components which are passed into the cabin itself, as indicated by the 340$G$ peak in Fig. $7 \mathrm{a}$ and $43-\mathrm{G}$ peak in Fig. $7 \mathrm{~b}$. Careful design of a controller box with moderate strength is required, with appropriate thinning of the chassis rails as was done in Design " $M$ ". This design forces the fowertrain into motion early on, so that during an NCAP or more severe impact, G's transferred from the powertrain to the cabin are minimized as the 34-G peak in Fig. $7 \mathrm{~b}$ shows.

Design " $M$ " represented the final iteration for the frontal model during this study and represents the current best compromise for survival and intrusion during the impact conditions of FMVSS 208, NCAP, and deep crush conditions. The qualitative features of this design during the progression through deep crush are shown from different perspectives in F!gs. 8-11. The Fig. 8 sequence shows a sectioned view through the centerline of the vehicle, illustrating the motion of the powertrain. Fig. 9 shows an external side view highlighting the wheel/tire impact with tire blowout potentially occurring at the higher velocity of $v=26.8$ $\mathrm{m} / \mathrm{s}$. In Flg. 10, the wheel/tire is removed from the plots to show the progression of buckling and motion in the midrail and toprail. Fig. 11, a top view, highlights the motion of the wheel and tire assembly, which minimizes their effects as hard points during deep crush. The assemblies are influenced by the suspension and structure toward a toe-in condition so that energy absorption in deep crush is again controlled by the structure forward of the cabin. 
a)



b)

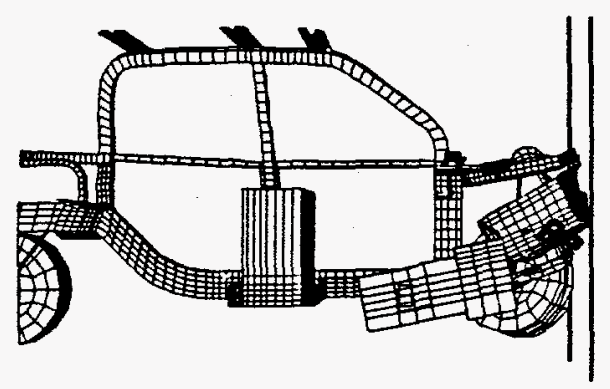

c)

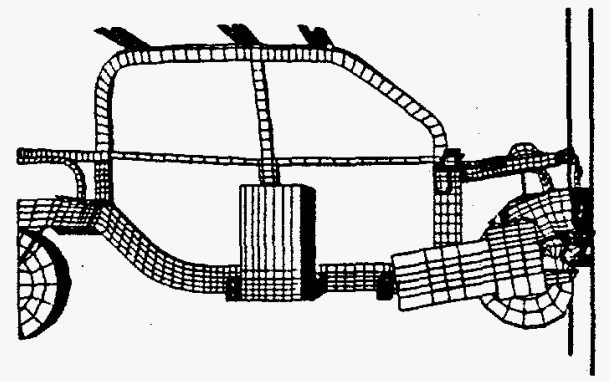

d)

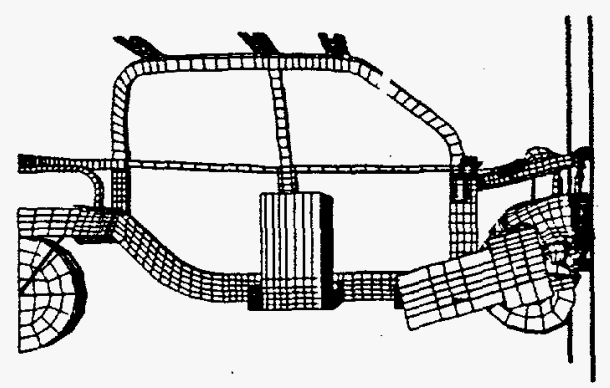

e)

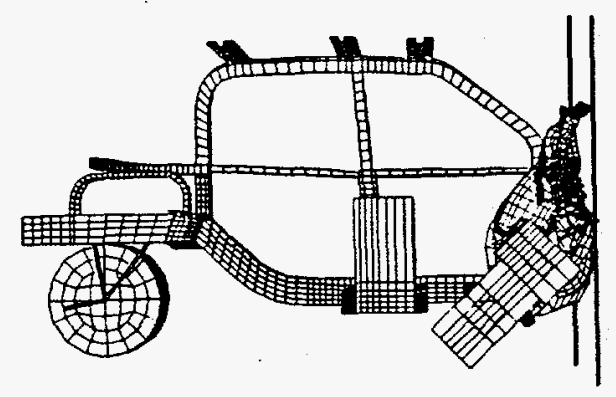

Fig. 8. Crush sequence from vehicle centerline. a) initial. b) after $v=13.4 \mathrm{~m} / \mathrm{s}$ impact. c) Same crush distance (51 $\mathrm{cm}$ ) from $v=26.8 \mathrm{~m} / \mathrm{s}$. d) Crush of $64 \mathrm{~cm}$ from $v=26.8$ $\mathrm{m} / \mathrm{s}$, NCAP crush level. e) Complete crush of clip at 105 an. a)

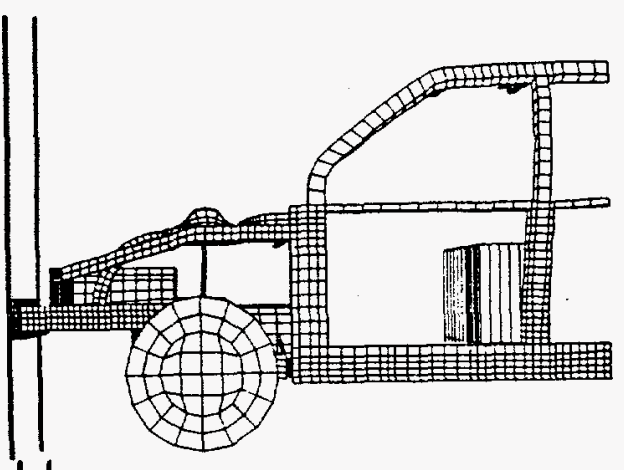

b)

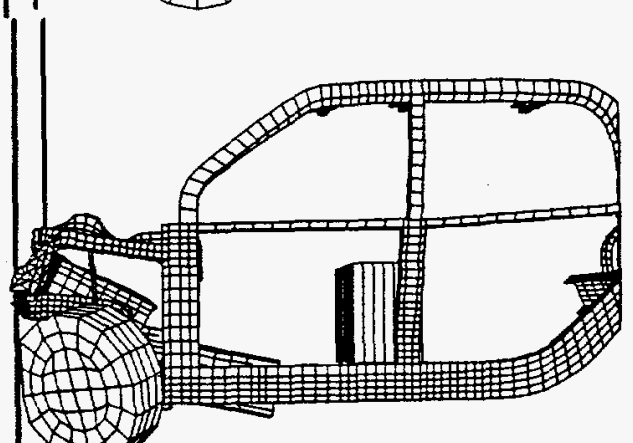

c)

d)

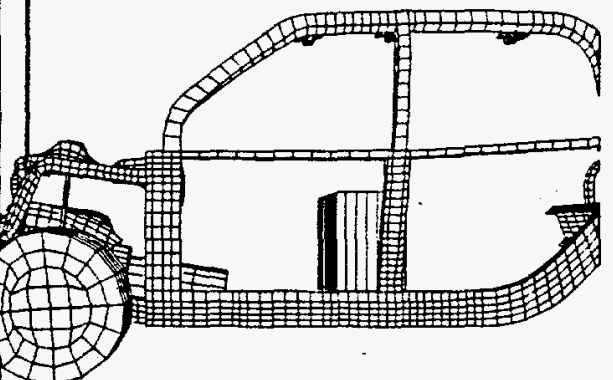

e)



Fig. 9. Crush sequence, external side view. a) initial. b) after $v=13.4 \mathrm{~m} / \mathrm{s}$ impact. c) Same crush distance $(51 \mathrm{~cm})$ from $v=26.8 \mathrm{~m} / \mathrm{s}$. d) Crush of $64 \mathrm{~cm}$ from $v=26.8 \mathrm{~m} / \mathrm{s}$, NCAP crush level. e) Complete crush of clip at $105 \mathrm{~cm}$. 
a)

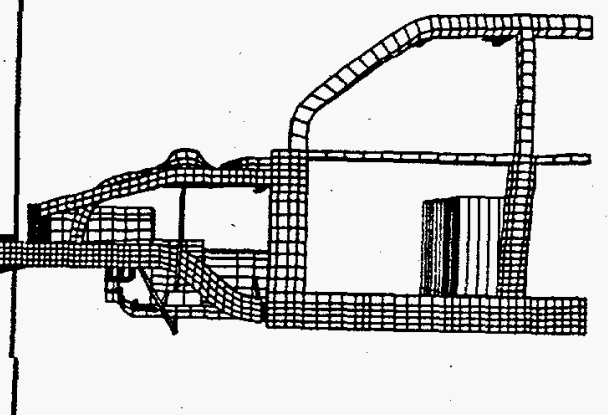

b)

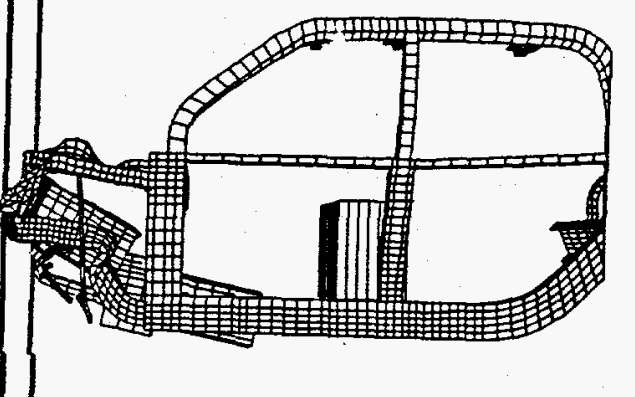

c)

d)

e)

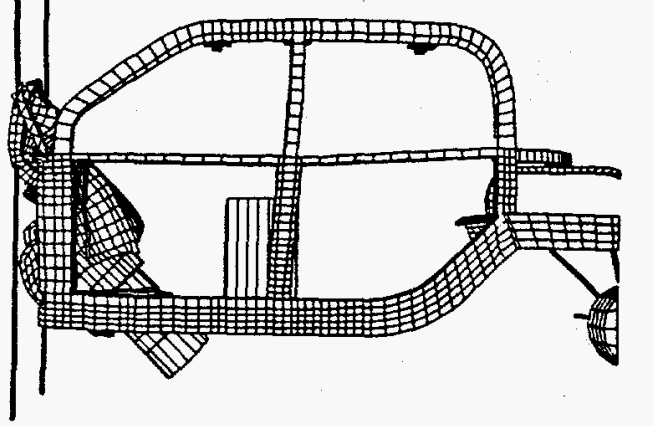

Fig. 10. Crush sequence, side view, wheel/tire deleted. a) initial. b) after $v=13.4 \mathrm{~m} / \mathrm{s}$ impact. c) Same crush distance $(51 \mathrm{~cm})$ from $v=26.8 \mathrm{~m} / \mathrm{s}$. d) Crush of $64 \mathrm{~cm}$ from $v=26.8 \mathrm{~m} / \mathrm{s}$, NCAP crush level. e) Complete crush of clip at $105 \mathrm{~cm}$. a)

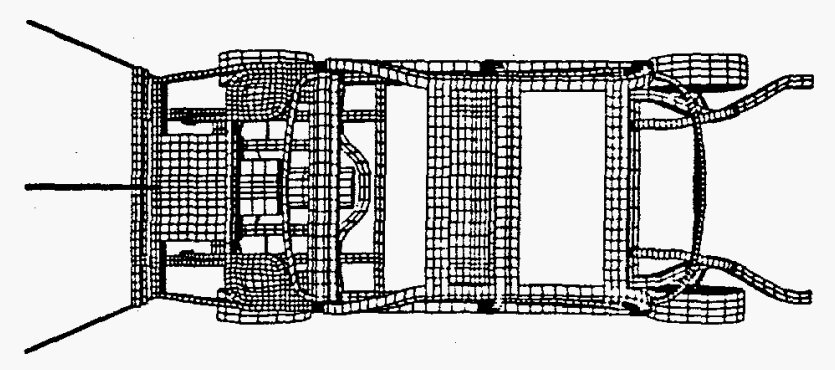

b)

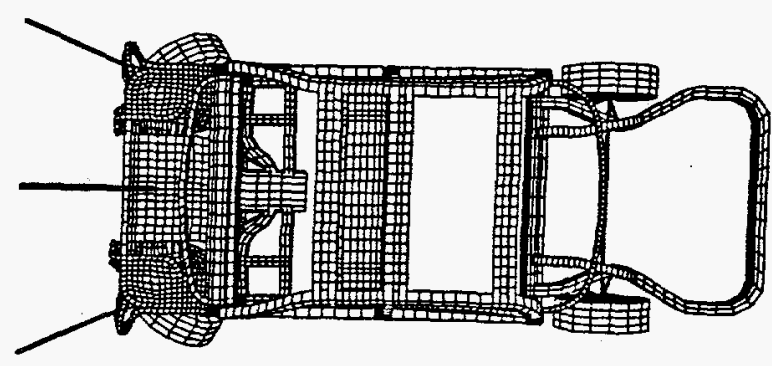

c)
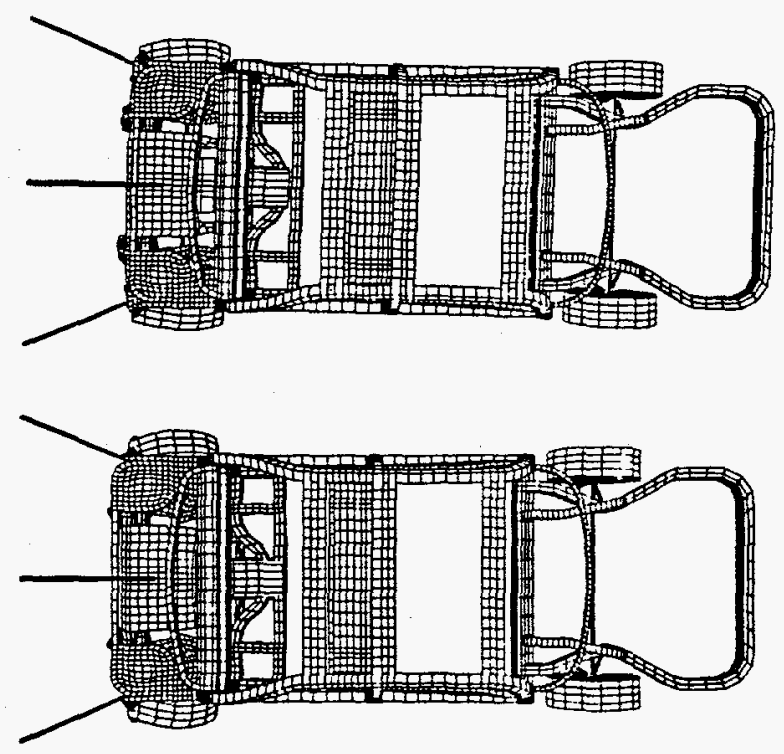

d)

e)

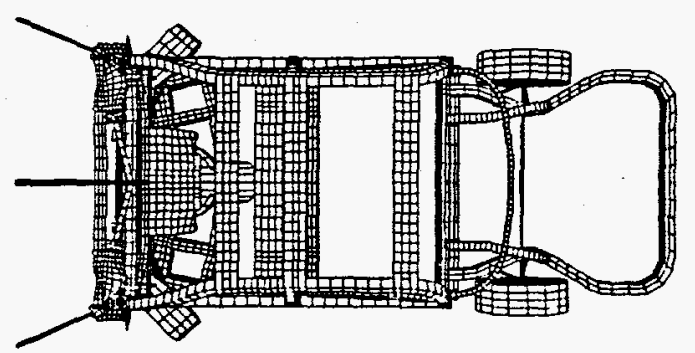

Fig. 11. Crush sequence, top view. a) initial. b) after $v=13.4 \mathrm{~m} / \mathrm{s}$ impact. c) Same crush distance $(51 \mathrm{~cm})$ from $v=26.8 \mathrm{~m} / \mathrm{s}$. d) Crush of $64 \mathrm{~cm}$ from $v=26.8 \mathrm{~m} / \mathrm{s}$, NCAP crush level. e) Complete crush of clip at $105 \mathrm{~cm}$. 
The sequences in Figs. 8-11 show the dramatic constraints encountered in deep crush design, and yet they illustrate the relative ease with which one may design to the FMVSS 208 standard crush condition. Plot (a) in each figure shows the undeformed structure just before impact. Plot (b) shows the final state at rest after the FMVSS 208 impact. Permanent crush distance is about $51 \mathrm{~cm}$ for this impact, with B-pillar G's as shown in Fig. 12 at $v=13.4 \mathrm{~m} / \mathrm{s}$. In plot (c), deformations are shown at the same crush level, but during the early portion of a high-speed $v=26.8 \mathrm{~m} / \mathrm{s}$ impact. Apparent is the reduced time available for motion and rotation of the powertrain and wheels compared to the geometry at the same crush level but lower initial speed as in the (b) series of each figure. This is manifest in Fig. 12 as a somewhat higher deceleration level at the B-pillar. The (d) series of each of Fig. 8-11 shows a crush level about equivalent to the NCAP impact condition. Even with the high velocity used here, motion and direction of the powertrain and wheels are clearly established at this point so that the backup structure can assist in managing deeper crush levels. Recall from the motor G's of this design (" $\mathrm{M}$ " in Fig. 7a) that the motor has been accelerated to its near-final velocity by this point (just under $30 \mathrm{~ms}$ in the DYNA run). At this point, the overall cabin G-level is designed to increase as needed to stop the vehicle during complete crush of the front clip from an approximate $v=22.3 \mathrm{~m} / \mathrm{s}$ initial impact speed. The toprail has done its job of controlling the crush geometry, providing for a high axial component to the midrail crush.

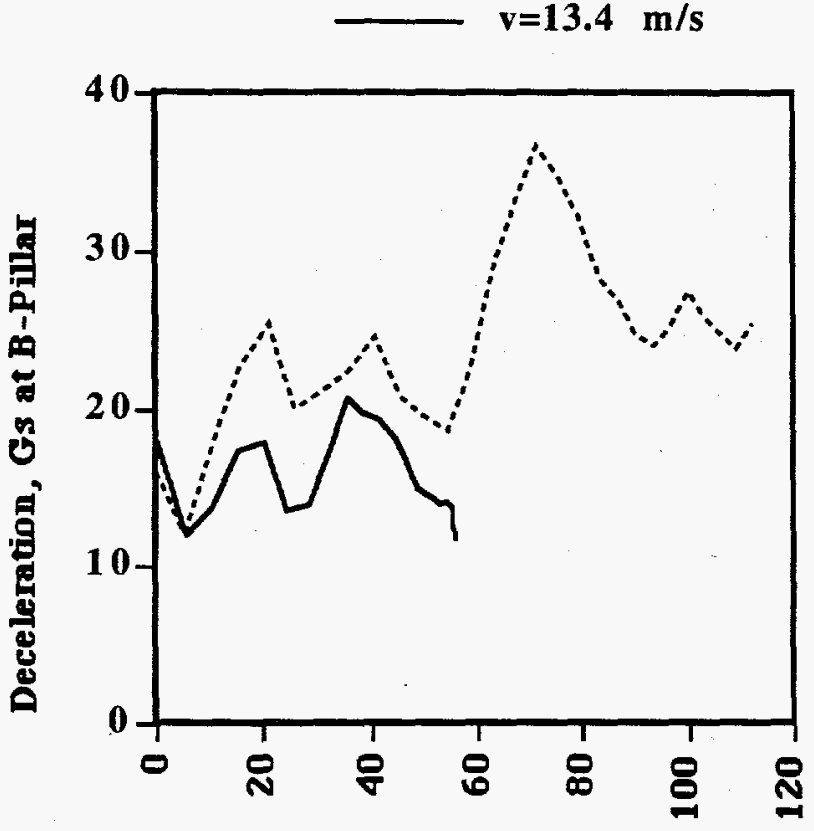

Crush, cm

Fig. 12. Comparison of deceleration vs. crush showing effect of initial impact velocity (FMVSS 208 speed or double speed).

This action is limited somewhat by the necessary rotation and motion of the powertrain down under the floorpan area. Still, the integrity of the cabin is maintained during the NCAP test with minimal intrusion and a relatively smooth deceleration history.
Beyond the NCAP crush level, behavior of the front clip is controlled by crush of the strut tower rails and assembly, with deformation of the cowl and rocker rail beginning to contribute during the vehicle stop from $v=22.3 \mathrm{~m} / \mathrm{s}$. However, even at this near-interstate impact speed the design has the potential to avoid massive intrusion and undue spikes in the deceleration sequence. In doing so, design for the FMVSS 208 impact has largely taken care of itself except for some model-specific refinements.

Considering the large effect of the powertrain and controller on crush behavior, we proceeded to do a parametric study on the base " $M$ " design to study the sensitivity of vehicle response to the presence of major components and thicknesses of the major rails in the front clip. These results are shown graphically in Figs. 13-14. These figures show the crush behavior of the front end during a $v=26.8 \mathrm{~m} / \mathrm{s}$ impact, at approximately the FMVSS 208 crush level of $51 \mathrm{~cm}$. Fig. 13a shows again the base " $M$ " behavior. For Fig. 13b, the DYNA run was made without the motor/transaxle/controller assembly. The result is more buckling in the " $S$ " portion of the midrail, but less rotation of the toprail which is caused by the powertrain when it is present. As a comparison, the run for Fig. $13 \mathrm{c}$ was made without the wheeltire/spindle assembly. The effects are more subtle than ihe absence of the powertrain, but more rotation and midrail crush can be observed since some of this work had gone into accelerating the wheel/tire assembly previously. Fig. 13d illustrates the effect of removing the toprail from the structure. Increased rotation of the entire front clip is evident, which would become more severe at deeper crush levels. For the run in Flg. 13e, the strut rail (pair of curved extrusions building the MacPherson strut tower) is removed, resulting in effects similar to removing the toprail, but with less severe rotations.

Fig. 14 examines the effect of thickness of the two major front rails. Starting with the basic " $M$ " design, the midrail is thickened by a factor of $\times 1.414$ for Flg. $14 a$, resulting in visibly less crush of that rail. However, as discussed later, one effect of this change is that rotations are increased as the load now follows a weaker path toward the top of the structure. Conversely, if the midrail is made thinner by $x .707$ as in Flg. 14b, the axial crush tendency of the midrail is regained but with less energy absorbed as quantified below. For Fig. 14c, the toprail was thickened by the same $x 1.414$. The result is slightly less crush overall, with less rotation of the strut tower area. However, the major effect of the toprail is still to bend and control the geometry of the crush. Thinning the toprail by $x .707$ as shown in Flg. 14d increases the rotation tendency as did its removal in Fig. 13d. Similar permutations were performed with strut rail and cradle thickness but the results were too subtle for overall observation graphically. 
a)

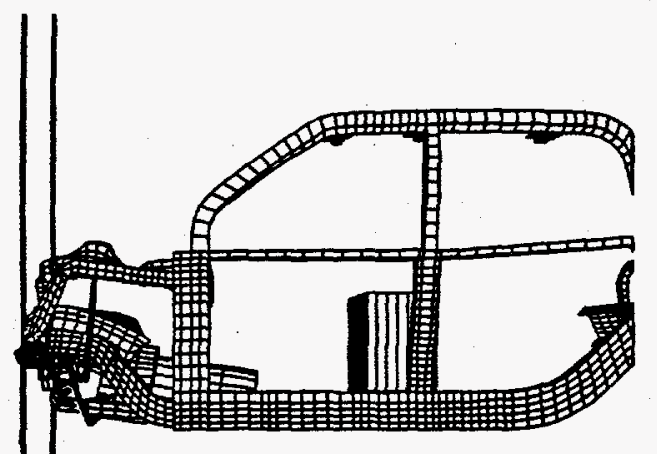

b)

c)

d)

e)

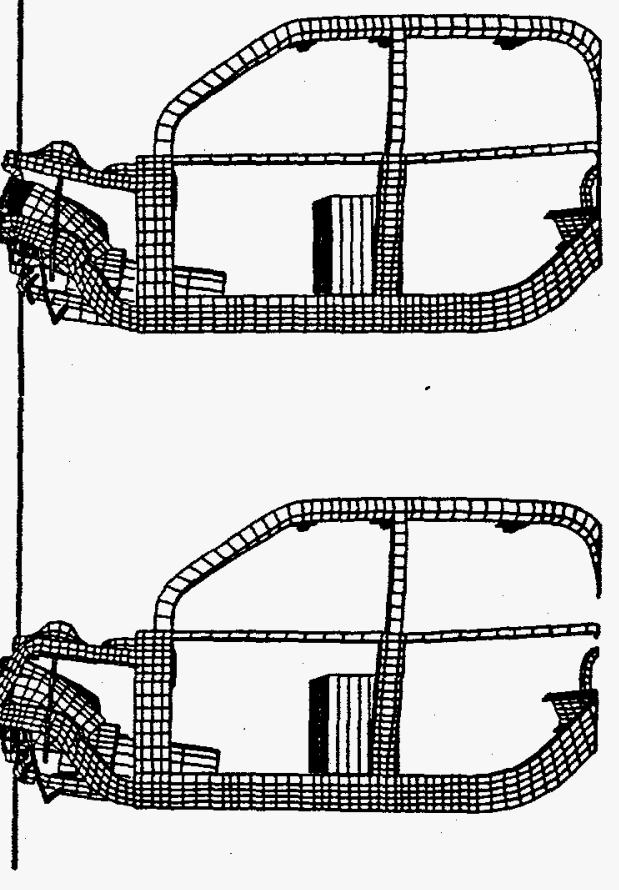

Fig. 13. Crush profile at $51 \mathrm{~cm}$, side view (wheel removed from plots). a) Base " $M$ ". b) Powertrain removed. c) Wheel/tire/spindle removed. d) Toprail removed. e) Strut rail removed. a)

b)

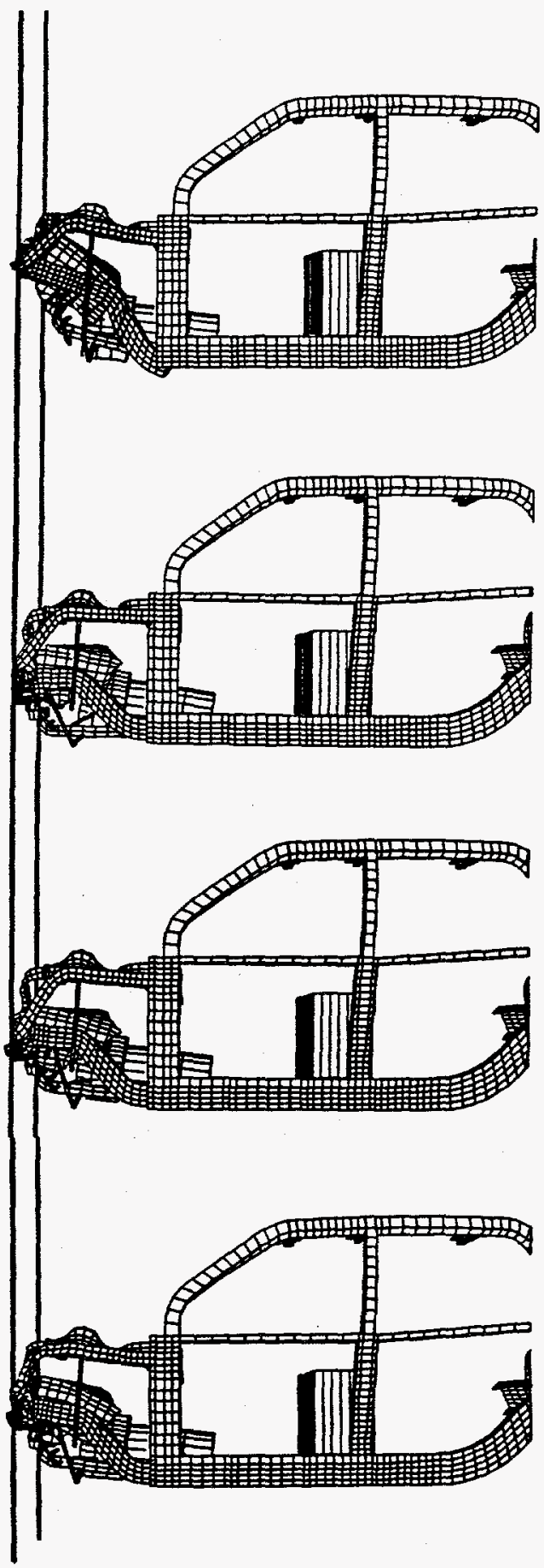

Fig. 14. Effect of rail thickness on crush profile at $51 \mathrm{~cm}$, side view (wheel removed from plots). a) Midrail $\times 1.414$. b) Midrail $\times 0.707$. c) Toprail $\times 1.414$. d) Toprail $\times 0.707$. 
The bar chart shown in Fig. 15 is helpful in quantifying some of the effects observed graphically in the previous figures of crush profiles. In this chart, we compare the energy absorption of the full vehicle for the different configurations studied above. With the exception of the first two bars, all indicate kilojoules of energy absorbed at a level of $50 \mathrm{~cm}$ of crush during the high speed $v=26.8 \mathrm{~m} / \mathrm{s}$ impact simulation. The first bars allow comparison of the energy absorbed at $100 \mathrm{~cm}$ vs. $50 \mathrm{~cm}$ for the " $\mathrm{K}$ " and " $\mathrm{M}$ " designs (refer to Fig. 7 for $\mathrm{G}$ profile). The " $M$ " structure is slightly softer overall and as noted previously has a much smoother deep crush signature. In both cases, the energy absorbed at $100 \mathrm{~cm}$ (342 kJ for " $K^{\prime \prime}, 332 \mathrm{~kJ}$ for " $\mathrm{M}$ ") is over twice that at $50 \mathrm{~cm}$ (151 and $140 \mathrm{~kJ})$. In the absence of the motor $(-M T / T X L)$, energy absorbed (EA) drops from 140 to $118 \mathrm{~kJ}$ in the " $M$ " design. Deleting the wheel (-WHLTTRE) causes a drop to $131 \mathrm{~kJ}$. Removing the toprail (-T.RAIL) has a more striking effect than visible even graphically (Fig. 13d) as EA drops to $100 \mathrm{~kJ}$. Removing the strut rail (S.RAIL) drops EA to $114 \mathrm{~kJ}$, as this rail does not come into full play until after the 208 crush point. Changes in thickness to the midrail (M.RAIL) have the most pronounced effect on energy absorption. Thus, once the geometry of the midrail crush is controlled, its thickness dominates the behavior of the frontal crush signature. The toprail thickness changes show some influence but the mere presence of the toprail and strut rail are more important than their thickness as will be illustrated later.

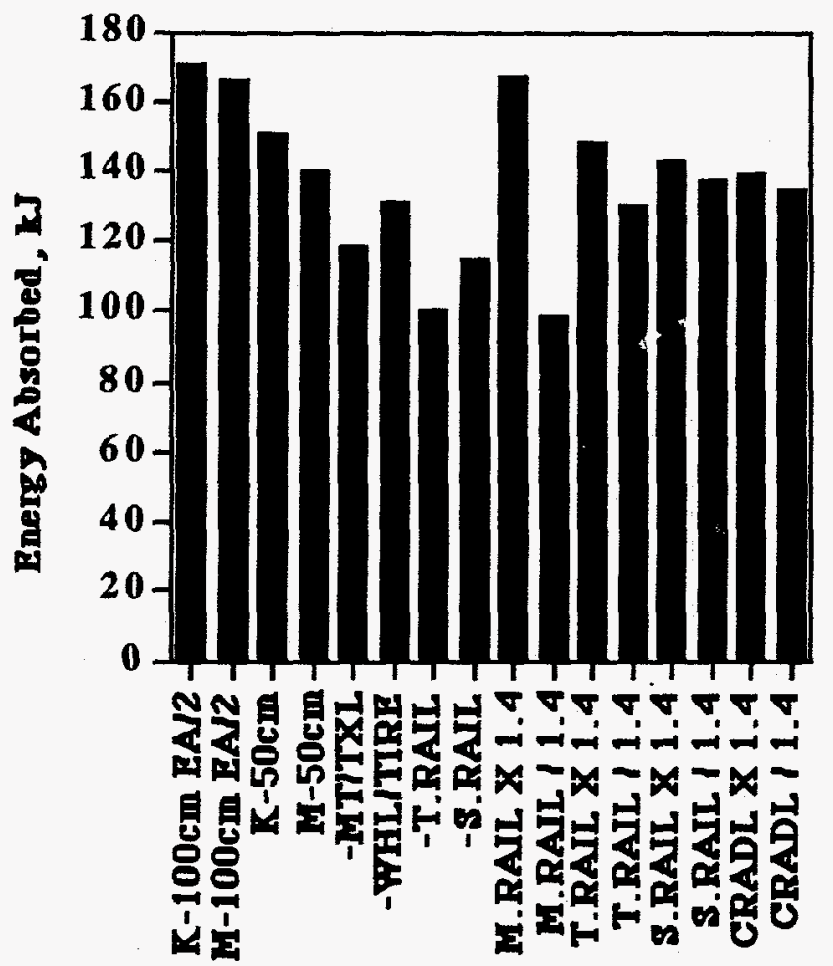

Fig. 15. Effect of design permutations on full-vehicle energy absorbed at crush of $100 \mathrm{~cm}$ or $50 \mathrm{~cm}$ during $\mathrm{v}=26.8 \mathrm{~m} / \mathrm{s}$ impact.
As a companion chart, Flg. 16 was prepared to show the effect of the design permutations on another crucial design goal. The overall G-level for a given impact scenario becomes constrained by the overall length of the front clip, in addition to allowances for high speed impact. However, for durations over a few milliseconds, the peak-to-average G-level is very important in determining injury potential. Some minor variations may be smoothed by the restraint system, but as seen in Fig. 7 above, it is possible and desireable to smooth the G's seen by the cabin floorpan as much as possible in the front clip design. The permutations explored in Fig. 15 also show some interesting trends regarding the G-peak/G-avg. (pklavg) ratio. The first two bars compare the " $K$ " and " $M$ " designs at near-complete crush of $100 \mathrm{~cm}$. Note the pklav ratio is reduced from 1.69 to 1.47 in going to the " $M$ " design. At $50 \mathrm{~cm}$ crush, the difference is not visible between the two at 1.22. However, removing or charıging components can change the pklavg ratio even at $50 \mathrm{~cm}$ crush. Removing the motor/transaxle raises the ratio, as crush is easier at first until a hard point is reached. Removal of the wheel assembly is clearly desireable (pk/avg only 1.07) but obviously not possible. Deleting the toprail actually improves the pk/avg to 1.17 but with poor consequences at deeper crush. Removing the strut rail causes a surprising increase in pkav to 1.40, as does changing the midrail thiikness in either direction. This implies that this most important rail is in the ballpark of the correct thickness and behavior. Changes in other

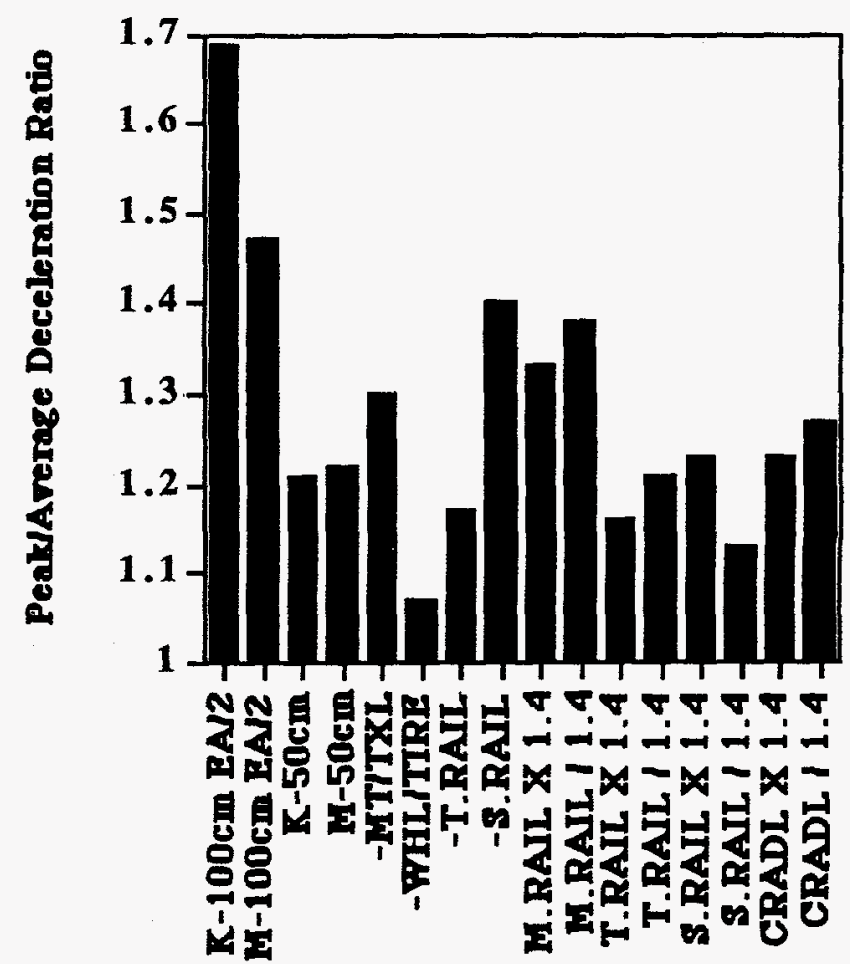

Fig. 16. Effect of design permutations on Peak-toAverage deceleration ratio at the B-pillar. 
- thicknesses (toprail, strut rail, cradle) have a lesser effect. As stated above, their presence and geometry seems to be more important than exact thickness if held within reason.

We noted above the dependence of energy absorption on member thickness of about $t^{1.6}$ to $t^{1.8}$ power. We can examine this dependence for the rails in the full vehicle using the DYNA simulation data as plotted in Fig. 17, showing energy absorbed vs. relative thickness of the rail. For the case of the toprail and strut rail, we can delete these totally, but the midrail can only be adjusted in thickness. However, in either case, energy absorbed (full vehicle) does not show a superlinear dependence on any of the rails. This is likely due to the effect observed graphically above wherein the energy tends to be redirected rather than absorbed as a given member is made thicker. The same effect is noted again in Fig. 18, where we plot energy absorbed vs. mass of each pair of rails. A regression line gives a crude approximation to the specific energy absorption of the rails as they perform in the vehicle under a combination of axial, bending, and redirecting functions. The midrail value of $19.5 \mathrm{~kJ} / \mathrm{kg}$ compares well with values of $35 \mathrm{~kJ} / \mathrm{kg}$ considered as good perfomance for aluminum in pure axial crush [8]. On average, the toprail and strut rails show lower values of 13.2 and $10.2 \mathrm{~kJ} / \mathrm{kg}$, but again it is apparent that their presence is more crucial than thickness. The initial slope for these rails indeed approaches $20 \mathrm{~kJ} / \mathrm{kg}$ as for the midrail.
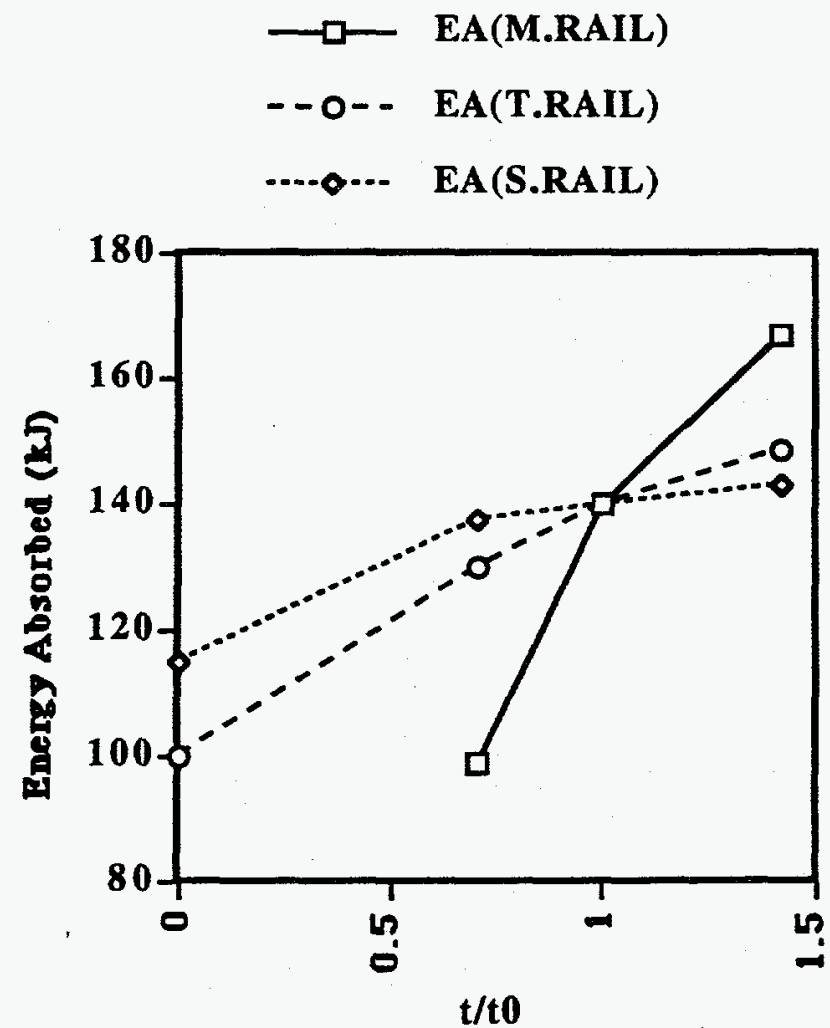

Fig. 17. Dependence of energy absorbed at $50 \mathrm{~cm}$ crush on relative thickness for midrail, toprail, and strut rail pairs in the full vehicle.

This work was performed under the auspices of the US. DOE by LUNL under contract no. W-7405-Eng-48.
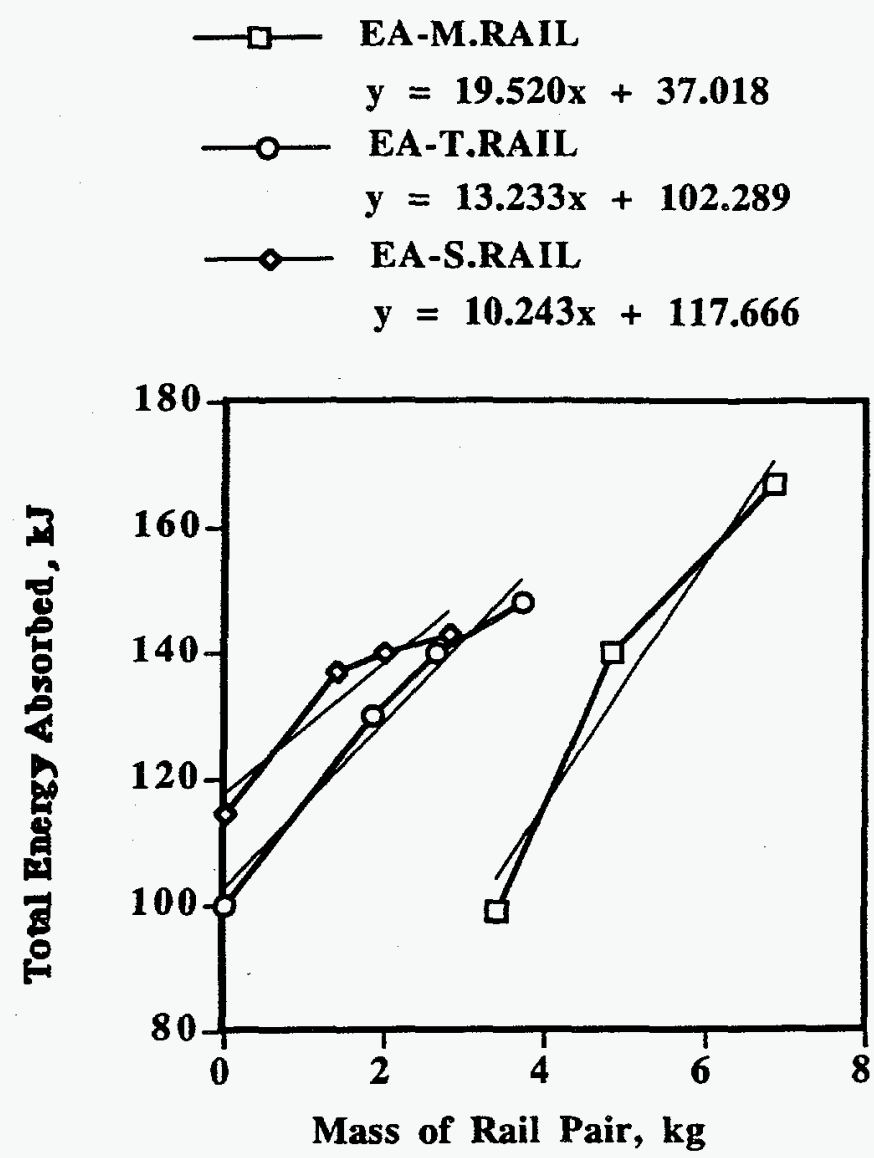

Fig. 18. Dependence of $50 \mathrm{~cm}$ crush energy absorbed on mass of a given rail pair. Regression fits provide overall slopes in $\mathrm{kJ} / \mathrm{kg}$ for each rail pair, with initial slopes more effective.

\section{SUMMARY AND FUTURE WORK}

The current prototype represents a stepping stone toward a balance of weight reduction and safety. Based on lessons learned from the first chassis built, we have discovered means of improving the frontal crush characteristics of the vehicle while allowing for flexibility in the size and weight of powertrain components in the front end. These are incorporated with relative ease due to the versatility of the extrusion manufacture and assembly process. The efficiency of the DYNA model permits similar versatility in exploring further design permutations with quick tum-arounds of several hours at the desktop workstation level for full frontal impact.

\section{ACKNOWLEDGMENTS}

The authors wish to acknowledge the support of the CALSTART consortium and their funding sources, as well as the help and support of Dr. L. Bell and $K$. Gunning at Amerigon. The assistance of $J$. Reiswig of LLNL in model development and L. Ensign at Kaiser Aluminum in testing assisted in the foundations of the work. R. Rainsberger at $X Y Z$ provided assistance through several crises, and S. Summers at NHTSA as well as informal Detroit area sources provided candid comments and suggestions on the design. 
This work was performed in part under the auspices of the U.S. Department of Energy by the Lawrence Livermore National Laboratory under contract W-7405-Eng-48.

\section{REFERENCES}

1. Maker, B.N., "NIKE3D, A Nonlinear, Implicit, ThreeDimensional Finite Element Code for Solid and Structural Mechanics - User's Manual", UCRL-MA-105268, (1991).

2. Whirley, R.G., "DYNA3D, A Nonlinear, Explicit, ThreeDimensional Finite Element Code for Solid and Structural Mechanics - User's Manual", UCRL-MA-107254, (1991).

3. Mahmood, H.F. and Paluszny, A., "Design of Thin Wall Columns for Crash Energy Management - Their Strength and Mode of Collapse", SAE 4th International Conf. on Vehicle Structural Mechanics, Nov. 1981, Paper No. 811302.

4. Wierzbicki, T. and Akerstrom, T. "Dynamic Crushing of Strain Rate Sensitive Box Colummns", SAE 2nd Intemational Conf. on Vehicle Structural Mechanics, Apr. 1977, Paper No. 770592.

5. Logan, R.W., "Tire, Accident, Handling, and Roadway Safety, "Engineering Research and Development Thrust Area Report FY92,, ed. S.Y. Lu, LLNL, UCRL-53868-92 (1992).

6. McMichael, L.D., "Evaluation of a Space Frame Impact Cage for Weapon Transport," LLNL, UCRL-ID-113094, (1993).

7. Wekezer, J.W., Oskard, M.S., Logan, R.W. and Zywicz, E. , "Vehicle Impact Simulation", J. Transp. Engr., Vol. 119, No. 4 (1993).

8. Logan, R.W. , Burger, M.J. , McMichael, L.D. and Parkinson, R.D. , "Crashworthiness Analysis Using Advanced Material Models in DYNA3D", ASME AMDVol. 169, Crashworthiness and Occupant Protection in Transportation Systems, Eds. J.D. Reid and K.H. Yang (1993).

9. Banthia, V.K., Miller, J.M., Valisetty, R.R., and Winter, E.F.M., "Lightweighting of Cars with Aluminum for Better Crashworthiness", SAE Paper No. 930494, Mar. 1993.

10. McGregor, I.J., Nardini, D., Gao, Y., and Meadows, D.J., "The Development of a Joint Design Approach for Aluminum Automotive Structures", SAE Paper No. 922112, Sept. 1992.

11. Nordmark, G.E., Miller, J.M., and Banthia, V.K., "Joint Design for Aluminum Automotive Structures", SAE Paper No. 930492 , Mar. 1993.

12. "Pro/ENGINEER, Mechanical Design Automation For Design-Through Manufacturing", Parametric Technology Corp., Waltham, MA (1993).

13. "TrueGrid, Version 1.2.2, User's Manual", XYZ Scientific Applications, Inc., Livermore, CA (1994). 